$\xi_{p}$

\title{
Dimensions and Sub-Dimensions for the Evaluation of M-Learning Apps for Children: A Review
}

\author{
Azham Hussain $^{1}$, Emmanuel O.C. Mkpojiogu' ${ }^{2}$, Fa'alina Hassan $^{1}$ \\ ${ }^{1}$ Human-Centered Computing Research Lab, School of Computing, Universiti Utara Malaysia, O6010 Sintok, Malaysia \\ ${ }^{2}$ Department of Computer and Information Technology, Veritas University Abuja, Nigeria \\ *Corresponding Author Email: azham.h@uum.edu.my
}

\begin{abstract}
The introduction and rapid growth of mobile learning applications (m-learning apps) has improved the role of teachers in facilitating the learning process especially among children. The learning experiences of children are enhanced and enriched with the use of $\mathrm{m}$-learning apps for children. There are several m-learning apps developed for children in the market today, however, some of these apps do not succinctly support and adequately assist in the learning process and educational endeavors and quest of these young minds. In this paper, a systematic review of literature was conducted to assess past research and studies on usability dimensions and sub-dimensions utilized in evaluating children's m-learning apps. The systematic literature review consisted of the following approach: the definition of search strategy, selection of primary studies, data extraction, and implementation of synthesis strategy and lastly, the presentation of findings. The result of the review reveals that effectiveness, efficiency, learnability, and user satisfaction (with their corresponding sub-dimensions) were the top four usability dimensions used in the evaluation of m-learning apps for children. In addition, the works reviewed showed that usability evaluation is prominent only during the implementation phase of the applications' development.
\end{abstract}

Keywords: Usability, Learning, Education, M-Apps, Children, Evaluation.

\section{Introduction}

In this period of mobile revolution, mobile devices are considered the most essential technology. The early part of the 1970's witnessed the era of computers; this was followed in the 2000's by the laptop era. The present times are no doubt the mobile device era. Mobile device innovations are expected to be used by almost everybody. Even toddlers as young as 3 years old can have and use mobile devices. Today, many large organizations and companies have converted or extended their computer-based applications to mobilebased applications due to the potentials and offerings that the mobile devices provide. Furthermore, to catch the attention of users to use these applications, the design of the mobile applications is very vital as it influences and captivates users to use them [1] [11-14].

Mobile devices are more and more becoming incorporated into the various aspects of our everyday life. One of such areas is in the educational sector; here mobile phones are employed as educational platform and implement to facilitate teaching and learning process. Mobile devices and services have the prospect of enhancing the process of learning and education, especially among children. Moreover, the utilization of computer-based learning has steadily become unfit for use because of the rapid development of mobile technology. Due to this, several activities are now being done using mobile devices. With the increasing advancement in mobile technology, the production and purchasing cost of mobile devices are surprisingly dropping lower and lower [10][20]. This paves the way for them to be accessible to so many people. Furthermore, over the years, usability has become a major indicator of the quality of software applications [21-22]. From the user's point of view, the interface of software application is the prominent constituent of the mobile device, because it is the users' main environment of interaction with the application. Moreover, usability definition does not only involve the process of interaction, but also the design of the interface. Changes to the design can be however expensive, if the inspection activities and usability evaluation were not carried out throughout the entire process of development [11-14] [20].

Since the applications for smart phones is in high demand and competitions are getting higher in mobile applications market [30], many developers and companies tend towards developing mobile applications faster to meet up with consumers demand [30]. Usability testing is thus an inevitable and very important aspect of the application development; this ensures that the application does not lack any form of usability. The applications are tested on both emulator and mobile devices so as to understand their behavior on different platforms [29].

Many teachers obtain IT training by attending IT courses. However, as a result of their weak IT background, and the special needs in their work, the traditional approach based on lecture, which is adopted in many computer courses, are ineffective and boring [1]. Mobile-based learning applications have the potential of motivating and catching attention while also assisting users to center their focus on solving their problems, improving their memory, and enhancing 
their reading and writing. Further to the traditional classroom context, the use of advanced technology in the learning process and assessment via mobile learning test applications enable students' time management in accordance to their needs for a personalized learning experience [1][3-5] [7].

Mobile learning applications (m-learning apps) seem to be preferred by children, because these apps can potentially accommodate a variety of features and sections that offer an interactive learning experience. It offers an environment that is free of stress for children and enhanced with a user interface design that is friendly to kids. The design and layout of the text removes frustrations and confusion, and also make information resources easier to access and use. In fact, m-learning apps support children to carry on a larger amount of learning activities [34-35] [38] [41-42]. The interaction of children and learning through technology enhances their aptitude for mind mapping [16].

There are several m-learning apps developed for children in the market today, however, some of these apps do not succinctly support and adequately assist in the learning process and educational endeavors and quest of these young minds. These challenges are largely due to the lack of usability of these apps arising from the applications poor interfaces. These inadequacies have rather dampened the learning morale of children and discouraged them from the use of such apps, thus, making the teachers facilitating role more difficult and challenging.

This paper presents a concise and synoptic review on the important and common usability dimensions and sub-dimensions used in the evaluation of usability in m-learning apps for children. Systematic literature review (SLR) approach was used to review a number of studies and to summarize the available empirical evidence [15] [27]. In this paper, this approach provided a template to capture current usability dimensions and sub-dimensions used in past research. The purpose of this study is to review and capture the important usability dimensions and sub-dimensions used for the evaluation of the usability of m-learning apps for children.

\section{A. Usability Evaluation}

Usability, as defined by the ISO is "the capability of a software product to be understood; learned, used, and attractive to the user, when used under specified conditions" [17]. A more generic approach is used in the assessment of the usability of applications in learning contexts. In the study of usability, the following criteria are often considered: learnability, efficiency, memorability, user satisfaction, effectiveness, simplicity, performance and understanding $[20,21]$. With reference to the children context, usability explains the ease with which children complete certain tasks, the speed of their performance and the amount of mistakes they make during the process of using an application [28]. One of the forms of measuring these criteria is usability testing. The understanding and readability of the content and the ability to remember information and application function, is part of a significant evaluation outcome that assists in the improvement of the applications [23].

Furthermore, making the user interface or content adapt to the user is another approach to improving usability. Making information personally available in a given context is one way of adapting to the user. The diversity of rationales for the use of mobile technologies in learning makes it challenging to make any generalizations about requirements. Nonetheless, there are attempts to characterize requirements, in association with interface design and usability.

Usability is mainly looked at from the perspective of issues or problems encountered by users, however, good usability basically implies that learning can proceed without hitches and might even be promoted by the availability of certain features. One of the major aspects of a successful and usable learning application is ease of use
[21] [26]. Many high quality applications in the market today actually lose out due to their complexity, unattractiveness and confusing user interface [20] [30]. Therefore, when designing a user interface for mobile phones and devices, especially for learning purposes, the user usability requirements of these devices should be of utmost interest [2] [24].

Interestingly, usability has been less extensively covered when compared to the other technological aspects of the m-learning apps. Mobile technology can be successful as an learning platform only when future studies into the area of m-Learning includes fruitful discussion on all aspects of usability such as learnability, understandability, ease of use, effectiveness, and efficiency etc, of mobile applications [2] [25].

The main aim of this study is to review the usability literatures on the usability dimensions and sub-dimensions of m-learning apps for children. The paper is organized as follows: section 2 provides the methods used for the study. The section includes the strategy for literature search, primary studies selection, extraction of data, and implementation of synthesis strategy; section 3 presents results and discussion on the systematic review, while section 4 concludes with the conclusions and future work.

\section{Methods}

Systematic literature review (SLR) approach was used in this study. The paper discusses the relevant and appropriate usability dimensions and sub-dimensions used for the evaluation of $\mathrm{m}$ learning apps for children. This approach was applied in the collection and analysis of previous studies carried out by other researchers in the past. The study reveals vital dimensions and subdimensions used in designing and evaluating m-learning apps for children. In order to enable the process of the systematic review, the following systematic literature review methods were carried out: search strategy definition, primary studies selection, data extraction, and synthesis strategy implementation (60-61).

Computers, nowadays, have become one of the most essential appliances that people possess. With the mobile internet revolution, human lifestyle has changed drastically, as people now communicate with other people around the world with great ease and speed. A substantial amount of research is being done to explore the advantages of using Information and Communication Technology as a learning platform for individuals, especially children with learning difficulties and challenges [29].

The main drive of this study is to assess the usability of m-learning apps with regard to how they affect the mobile learning experience of children, as well as the consequences and advantages they present to children. M-learning apps interplay and interwove computer technology and mobile e-learning. They combine individualized learning with anytime and anywhere learning. With the expansive wave of the internet, children can obtain lessons, notes and tutorials just by the click of their fingers on the application's screen and browsing of the internet. Usability testing is an important task that ensures that applications meet customer needs and do not lack any aspect of usability [8-9] [15]. Testing is compulsory as the applications have an enormous responsibility of meeting the user's needs and expectations. In addition, testing is also important because the development of the applications is been carried out fast and in great numbers due to the high competition and demand for the apps in the market.

\section{B. Strategy for Literature Search}

Several studies in this field were searched and only studies that are related and relavant to this review were selected. In order to perform the search and selection of research studies, two processes were 
defined, namely, search process and study selection.

The search strategy was defined based on the scope, involvement, and outcome criteria, in order to carry out the search and selection of research studies. The terms of the search were carefully chosen, taken into consideration the usability, learning, education and interference of the child's age and behavior. The basic search strings were defined after evaluating the different possible options for search terms.

a) Search Process: The search process consists of two phases: primary and secondary search. The primary search was done by means of fifty (50) online databases that enclosed references for scientific articles and journals, conference proceedings and technical papers like EdlTLib, Emerald, Google Scholar, Academia, ACM, Springer and IEEE Xplore [18].

In the secondary search, a thorough review was carried out for references and citations gotten during the primary search. In this case, the most relevant citations for the previously selected articles were, found, ensured and consolidated [18].

b) Study Selection: A set of specific selection criteria (inclusive and exclusive) to choose the most relevant studies for the systematic review was defined. The inclusion of studies was captured by the following criteria [18]:

- Usability methods that have been used in mlearning software development.

- Recommendations for the applications of usability methods in m-learning software development.

- Observations of user behaviors.

- Usability metrics, dimensions and subdimensions

- $\quad$ Reviews or similar systematic mappings.

\section{Primary Studies Selection}

This section identifies the selected journal for this study. A sum of 120 journals were found based on the keywords "usability", "evaluation", "children" and "education". However, only 50 out of 120 journals were selected for further review.

Data Extraction: The extraction of data procedure was primarily defined by the design of the data extraction forms that precisely registers the information gotten from the selected papers [15]. The content of the data extraction form comprised the following information, inter alia: (a) Paper title, (b)Author's name, (c) database engine contains the papers.

Synthesis Strategy Implementation: 120 journal papers from 7 databases were found. Following the application of the inclusion and exclusion criteria to the body of studies, 45 of them were selected for the review process. Then, after performing the secondary search process, 5 additional studies were selected, that summed up to 50 papers for the review. The details about studies found during the primary search process and the papers selected after the secondary search is provided in Table 1.

Table 1: Total articles classified by source databases.

\begin{tabular}{|c|c|c|c|}
\hline Database & $\begin{array}{c}\text { Found } \\
\text { Articles }\end{array}$ & $\begin{array}{c}\text { Duplicate } \\
\text { Articles }\end{array}$ & $\begin{array}{c}\text { Selected } \\
\text { Articles }\end{array}$ \\
\hline $\begin{array}{l}\text { Google } \\
\text { Scholar }\end{array}$ & 42 & 33 & 7 \\
\hline $\begin{array}{c}\text { IEEE } \\
\text { Xplore }\end{array}$ & 35 & 23 & 2 \\
\hline ACM & 31 & 18 & 6 \\
\hline EdlTLib & 9 & 3 & 9 \\
\hline Emerald & 1 & 0 & 0 \\
\hline Academia & 1 & 0 & 0 \\
\hline Springer & 1 & 0 & 1 \\
\hline Total & 120 & 77 & 50 \\
\hline
\end{tabular}

\section{Results and Discussion}

There were some results found in usability testing research [24-33]. These findings were captured from the observation of groups of children. The usability evaluating on m-learning apps for children has a few points of interest as follows: The first point is the hidden navigation. The screen space is very limited since mobile devices are small when compared to computers [30]. Developers need to employ the usage of the application in a very efficient way. The need for hidden navigation is very vital as space can be saved from unnecessary usage. Since navigation is an essential aspect in the applications, the user need to be informed that the navigation panel is hidden whenever it is not used before the applications are used. If not, some users might not understand the functioning of the navigation panel.

The second point is the clean interface. Clean interface in application design is proving to be a great pacesetter. Clean design implies that the application interfaces are simplified rather than adapting too much style, or color etc. Regardless of being a simplified design, it can still look stylish and perform efficiently. Apart from saving the space of the screen, it also reduces the time for application loading. Users might become offended and dissatisfied if the application takes a long time to load the interfaces that are seldom used.

The third point observed is the application design that can connect to other objects. Since mobile phones are a device that often sticks to its owner, mobile devices can be controlled with the use of remote control. For instance, Samsung recently released a washing machine that can be connected to Wi-Fi and controlled via smart phone application.

In addition, the studies reviewed also revealed that usability evaluations are conducted only during the implementation phase of the development lifecycle, and evaluation is often done as a description of the case study.

In this study, it is discovered that most researchers preferred the following dimensions as the best dimensions to be used for $\mathrm{m}$ learning usability evaluation: efficiency, effectiveness, learnability and user satisfaction. The mental and physical ability of children were also captured by researchers. The user interface of the application should therefore be very natural and intuitive to be used by all children (e.g. 6 to 10 years old children). The following four dimensions [15-22] with corresponding ten sub-dimension were found and selected from the reviewed papers.

1) EFFICIENCY: Efficiency is a resources expended in relation to the accuracy and completeness with which users achieve goals. The general usability of m-learning apps for children is a very significant factor, as the children do not want to struggle with the applications, just because they are not interested in the user interface [6]. From an efficiency point of view, the less time spent managing resource access, the more time is available to utilizing the value of those resources. There are unique demands for designing and administering apps for m-learning environment [10].Under efficiency dimension, three sub-dimensions were captured:

Compatibility: This sub-dimension has to do with compatibility issues, which might be varying depending on the type of mobile device in use and the children's aptitude to use them. As a result of smart phone becoming vital in our everyday life, almost everybody possesses a smart phone. Hence, children would prefer to learn through mobile because of its convenience and ease of use.

Loading time: This sub-dimension refers to the time spent on loading the application in the mobile device and how much time is taken for the app to respond to the user. It should be as fast as possible to respond because children concentrate less when the device respond time is too long. 
Accuracy: Accuracy refers to the performance measure where a specific task in an application is completed successfully and accurately, with no error, within a given time. In this case, the application should return accurate results. By integrating these three sub-dimensions, the efficiency of m-learning apps interfaces can be evaluated and measured.

2) EFFECTIVENESS: Effectiveness is the accuracy and completeness with which users achieve specified goals. Effectiveness in most studies is measured by how many answers are correct. In order to measure the effectiveness of the application interface, these two sub-dimensions were combined: Presentation and Navigation.

Presentation: This sub-dimension refers to how the buttons are presented. The buttons should be intuitive enough because the target users are children. Intuitiveness implies that the user will understand the meaning of the icons even without an accompanying explanation.

Navigation: Navigation menu should be in a logical structure where it makes sense for users to find the right content.

3) LEARNABILITY: Learnability of an application refers to a situation where the application is easy to learn so that the user can rapidly start getting work done with the application. Under learnability dimension, two sub-dimensions, namely: simplicity and familiarity, were captured. Simplicity and familiarity can be integrated together to measure the degree of effort needed for the user to learn the interface with a high degree of satisfaction. Learnability is in some sense the most fundamental usability quality [16]. The application should be easy to learn so that the user can rapidly start getting some work carried out with the application and achieve his or her goals. Learnability is especially essential to users who are novices.

Simplicity: This sub-dimension refers to the simplicity of the user interface. The interface should be as simple as possible for users to perform tasks with minimal effort.

Familiarity: This sub-dimension measures whether the application interface has elements that are familiar to the user in order to enable understanding.

4) USER SATISFACTION: User satisfaction is the freedom from discomfort, and positive attitudes towards the use of a product by a user. User satisfaction measures the application interface in term of content, user guide, and attractiveness. Satisfaction is a multidimensional construct. Majority of the studies utilized Likert scale to measure its directions and intensity ( $1=$ easy to use/high satisfaction, $5=$ difficult to use/low satisfaction). In addition to Likert scales used after each task, and in the post-test questionnaire, participants' comments are elicited. Furthermore, in addition to overall satisfaction and reaction, satisfaction are further assessed in the areas of ease of use, organization of information, terminology, labeling, visual appearance, content, error correction, best features, and worst features.

Content: This sub-dimension measures if the content of the applications fulfills user requirements and needs. User satisfaction can be measured to determine if the content has value to users.

User guide: This sub-diemension measures if the interface provides user manual to help users during their use of the application. User guide can be in the form of pop up message box rather than a long manual documentation. A long manual documentation will not be really needful in this case since the target users are children.

Attractiveness: This sub-dimension measures if the interface is attractive enough or unattractive to users. The interface should be attractive as well as engaging, visually appealing, colorful, beautiful and captivating to attract children to use it [23-33].

\section{Conclusions and Future Work}

Without mincing words, mobile phones are the way now and of the future. Designers and developers of m-learning apps for children need to put into consideration the usability issues of m-learning apps for children so as to be accepted to and usable by them. Usability dimension is perceived to be an essential guideline for developers to ensure that users carry out their tasks with convenience and ease. This study has identified selected usability dimensions and subdimensions that play important roles in the evaluation of the usability design and evaluation of m-learning apps for children. These dimensions and sub-dimensions were chosen based on past researches via a systematic literature review. Related conferences and journals papers were carefully reviewed. The study reveals that little attention has been given to research in the area of usability evaluation and design of children's m-learning apps. The study recommends that m-learning app for children should be designed and developed in such a way that they are easy to use, learnable, understandable, and attractive and should also offer a pleasurable and hedonistic experience for children. It is important to fulfill users' usability expectations and needs for the m-learning apps because user interface plays the most vital role for each interaction between the user and the smart phone application. Future work will focus on the development of a conceptual framework for evaluating the quality of m-learning apps for children. In addition, a prototype application for smart phones using Java Language and Android Software Development Kit will be constructed using as guideline the proposed framework.

\section{References}

[1] R.A. Aderinoye, K.O. Ojokheta, and A.A. Olojede, "Integrating mobile learning into nomadic education programme in Nigeria: Issues and perspectives," The International Review of Research in Open and Distributed Learning, vol.8, no.2, 2007.

[2] R. Skiada, E. Soroniati, A. Gardeli, and D. Zissis, "EasyLexia: A mobile application for children with learning difficulties," 5th Int'l Conf. on Software Development \& Technologies for Enhancing Accessibility \& Fighting Info-exclusion, 2013.

[3] R. Albalawi, "Evaluating tangible user interface-based mobile-learning system for young children," 2013.

[4] A. Ali, M.A.O. Alrasheedi, and L. Fernando, "A study of the interface usability issues of mobile learning applications for smart phones from the user's perspective," Int'l J. on Integrating Technology in Education (IJITE), vol.3, no.4, Dec., 2014.

[5] B.A. Alsugair, G. Hopkins, T. Brailsford, and E. FitzGerald, "Does mobile technology support peer learning for Key Stage 3 children?" 7th Int'l Conf. on Intelligent Environments, 2011.

[6] A. Alsumait, and A. Al-Osaimi, "Usability heuristics evaluation for child e-learning applications,". In Proc. of the 11th ACM Int'l Conf. on Information Integration and Web-based Applications \& Services, pp. 425-430, Dec., 2009.

[7] J. Attewell, and C. Savill-Smith, "Mobile learning and social inclusion: focusing on learners and learning,". In Learning with Mobile Devices, Research and Development Conf. (mLearn), Rome, pp. 3-11, 2004.

[8] N.A.A. Aziz, "Children's interaction with tablet applications: Gestures and interface design," Int'l J. of Computer and Information Technology vol.2, no.3, May, 2013.

[9] C. Baber, M. Sharples, G. Vavoula, and P. Glew, "A learning space' model to examine the suitability of different technologies for mobile learning," Learning with mobile devices, vol.21, 2004.

[10] J.G. Caudill, "The growth of m-learning and the growth of mobile computing: Parallel developments," The Int'l Review of Research in Open and Distributed Learning, vol.8, no.2, 2007.

[11] X. Chen, C. Ragonesi, J.C. Galloway, and S.K. Agrawal, "Design of a robotic mobility system with a modular haptic feedback approach to promote socialization in children," IEEE Transactions on Haptics, vol.7, no.2, April-June, 2014. 
[12] T. Csata, "Evaluating non-functional requirements in mobile learning contents and multimedia educational software," Learning with mobile devices, vol.13, 2004.

[13] P. Dawabi, M. Wessner, and E. Neuhold, "Using mobile devices for the classroom of the future," Learning with mobile devices, vol.55, 2004.

[14] P. David, R. Hokyoung, and C. Mark, "A Design Requirements Framework for Mobile Learning Environments," J. of Computers, 2(4), 2007.

[15] S. Keele, "Guidelines for performing systematic literature reviews in software engineering," Technical report, EBSE Technical Report EBSE-2007-01: 1-57, 2007.

[16] J. Nielsen, “Usability Engineering,” Boston MA. Acad. Press, 1993.

[17] ISO IEC 9126-1:2001. "Software Engineering-Product Quality Part 1Quality Model," 2001.

[18] C. Salvador, A. Nakasone, and J. Antonio, "A systematic review of usability techniques in agile methodologies. IEEE

[19] A. Druin, "Mobile technology for children designing for interaction and learning," Morgan Kaufmann, 2009.

[20] A. Hussain, E.O.C. Mkpojiogu, and Z. Hussain, "Usability evaluation of a web-based health awareness portal on smart phone devices using ISO 9241-11 model,” Jurnal Teknologi, vol.77, no.4, pp. 1-5, 2015.

[21] A. Hussain, and E.O.C. Mkpojiogu, "An application of ISO/IEC 25010 standard in the quality-in-use assessment of an online health awareness system," Jurnal Teknologi, vol.77, no.5, pp.9-13, 2015.

[22] A. Hussain, and E.O.C. Mkpojiogu, "The effect of responsive web design on the user experience with laptop and smart phone devices," Jurnal Teknologi, vol.77, no.4, pp.41-47, 2015 ..

[23] S. Thomas, G. Schott, and M. Kambouri, "Designing for learning or designing for fun? Setting usability guidelines for mobile educational games," Learning with mobile devices, pp.173, 2004.

[24] S. Wood, and P. Romero, "User-centred design for a mobile learning application," Proceedings of the 3rd Mexican. Workshop on Human Computer Interaction (MexIHC'2010), 2010.

[25] R. Zhang, "Using Mobile Phones to Assist Children's Learning in Universeum," 2009..

[26] M.J.J. Edith, C.B. Eduardo, and B.B.C. Eval, "Tool for experimenting with concepts of mobile robotics as applied to children's education," IEEE Transactions on Education, vol.53, no.1, Feb., 2010.

[27] P.B. Muyinda, E. Mugisa, and K. Lynch, "M-learning: The educational use of mobile communication devices," Strengthening the Role of ICT in Development, vol.72, 2007.

[28] A. Kukulska-Hulme, and J. Traxler, (Eds.), "Mobile learning: A handbook for educators and trainers," Psychology Press, 2005.

[29] B. Parhizkar, W.A.K. Obeidy, S.A. Chowdhury, Z.M. Gebril, M.N. Ah Ngan, and A.H. Lashkari, "Android mobile augmented reality application based on different learning theories for primary school children," IEEE, 2012.

[30] E.O.C. Mkpojiogu, N.L. Hashim, and R. Adamu, R. "Observed demographic differentials in user perceived satisfaction on the usability of mobile banking applications," 8th Knowledge Management International Conference (KMICe'16), Chiang Mai, Thailand, 29-30 August, 2016.

[31] A. Hussain, and E.O.C. Mkpojiogu, "Usability evaluation techniques in mobile commerce applications: a systematic review," International Conference on Applied Science and Technology (ICAST'16), Kedah, Malaysia. AIP Conf. Proc., vol.1761, no.1, 2016.

[32] A. Hussain, and E.O.C. Mkpojiogu, "A systematic review of usability test metrics for mobile video streaming apps," International Conference on Applied Science and Technology (ICAST'16), Kedah, Malaysia, AIP Conf. Proc., vol.1761, no.1, 2016.

[33] A. Druin, G. Knell, E. Soloway, D. Russell, E. Mynett, and Y. Rogers, "The future of child-computer interaction," CHI 2011, May 7-12, 2011, Vancouver, BC, Canada, 2011. ACM 978-1-4503-0268$5 / 11 / 05$.

[34] H. Edwards, and R. Benedyk, “A comparison of usability evaluation methods for child participants in a school setting," In Proceedings of the 6th international conference on Interaction design and children pp. 9-16, 2007. ACM.

[35] L. Hanna, K. Risden, and K. Alexander, "Guidelines for usability testing with children,” Interactions, vol.4, no. 5, pp. 9-14, 1997.
[36] R. Harrison, D. Flood, and D. Duce, "Usability of mobile applications: literature review and rationale for a new usability model," Journal of Interaction Science, vol.1, no.1, pp. 1-16, 2013.

[37] A.S. Hashim, W.F. Wan Ahmad, and R. Ahmad, "Mobile learning course content application as a revision tool: The eEffectiveness and usability," International Conference on Pattern Analysis and Intelligent Robotics 28-29 June, 2011, Putrajaya, Malaysia

[38] J. He, J. Ren, G. Zhu1, S. Cai, and G. Chen, "Mobile-based AR application helps to promote EFL children's vocabulary study," IEEE 14th International Conference on Advanced Learning Technologies, 2014.

[39] J. Kadirire, "Instant messaging for creating interactive and collaborative m-learning environments," The International Review of Research in Open and Distributed Learning, vol.8, no.2, 2007.

[40] M. Kam, A. Agarwal, A. Kumar, S. Lal, A. Mathur, A. Tewari, and J. Canny, "Designing e-learning games for rural children in India: A format for balancing learning with fun," 2008.

[41] S. Kanala, T. Nousiainen, and M. Kankaanranta, "Using a mobile application to support children's writing motivation," Interactive Technology and Smart Education, vol.10, no.1, pp.4 - 14, 2013.

[42] A. Kukulska-Hulme, "Mobile usability in educational contexts: what have we learnt?" The International Review of Research in Open and Distributed Learning, vol.8, no.2, 2007.

[43] K. Peters, "M-learning: Positioning educators for a mobile, connected future," The International Review of Research in Open and Distributed Learning, vol.8, no.2, 2007.

[44] L. Qvortrup, "Knowledge, education and learning, e-learning in the knowledge society," Sam Funds Literature, 2006.

[45] P. Rainger, "Usability and accessibility of personal digital assistants as assistive technologies in education," Learning with mobile devices, 2004.

[46] T. Rekkedal, and A. Dye, "Mobile Distance Learning with PDAs: Development and testing of pedagogical and system solutions supporting mobile distance learners," The International Review of Research in Open and Distributed Learning, vol.8, no.2, 2007.

[47] Y.E. Shih, "Setting the new standard with mobile computing in online learning," The International Review of Research in Open and Distributed Learning, vol.8, no.2, 2007.

[48] R. Skiada, E. Soroniati, A. Gardeli, and D. Zissis, "EasyLexia: A mobile application for children with learning difficulties," 5th International Conference on Software Development and Technologies for Enhancing Accessibility and Fighting Info-exclusion, DSAI, 2013.

[49] A. Stone, and K.U. Thames, "Designing scalable, effective mobile learning for multiple technologies," Learning with mobile devices, 2004.

[50] R. Tahir, F. Arif, "Framework for evaluating the usability of mobile educational applications for children," The International Journal of ELearning and Educational Technologies in the Digital Media (IJEETDM) 1(1): 16-31The Society of Digital Information and Wireless Communication (SDIWC), 2014.

[51] J. Traxler, "Defining, discussing and evaluating mobile learning: The moving finger writes and having writ," The International Review of Research in Open and Distributed Learning, vol.8, no.2, 2007.

[52] N.A. Wahab, A. Osman, and M.H. Ismail, "Engaging children to science subject: A heuristic evaluation of mobile learning prototype," Second International Conference on Computer Engineering and Applications, 2010

[53] N.S. Yahaya, and S.N. Abdul Salam, “ Mobile Learning Application For Children: Belajar Bersama Dino. The International Conference On Communication and Media 2014 (I-COME'14), 18-20 October 2014, Langkawi, Malaysia 